\title{
Evolução histórico-conceitual da Cooperação Técnica Internacional Brasileira em Saúde
}

\author{
Historical and conceptual evolution of the Braziian International \\ Technical Cooperation in Health
}

\section{Evolución histórica y conceptual de la Cooperación Técnica Internacional Brasileña en Salud}

Eduardo Mazzaroppi | emazzaroppi@gmail.com

Fundação Oswaldo Cruz, Instituto Oswaldo Cruz. Rio de Janeiro, RJ, Brasil.

\section{Resumo}

O presente artigo traça a evolução histórica da cooperação técnica internacional brasileira e sua relação com a saúde pública, marcando os momentos de inflexão conceitual e a perspectiva atual do Brasil sobre o tema. Analisar essa evolução histórico-conceitual e a inserção brasileira na política global da saúde é o objetivo deste artigo, que tem como método a análise documental, apoiada em revisão da literatura, e metodologia qualitativa. O marco teórico apoia-se principalmente em autores da política externa brasileira, da saúde global e da diplomacia da saúde, além de relatórios de instituições nacionais e multilaterais envolvidas com a cooperação técnica internacional em saúde.

Palavras-chave: Saúde Pública; Saúde Global; Diplomacia da Saúde; Cooperação Técnica Internacional; Política Externa Brasileira.

\begin{abstract}
This article draws the historical evolution of Brazilian international technical cooperation and its relationship to public health, marking the moments of conceptual inflection and Brazil's current perspective on the subject. The purpose of this article is to analyze this historical and conceptual evolution and the Brazilian participation in the global health policy, which method is document analysis, based on literature review and qualitative methodology. The theoretical framework relies primarily on authors of Brazilian foreign policy, global health and health diplomacy, as well as reports of national and multilateral institutions involved in international technical cooperation in health.
\end{abstract}

Keywords: Public Health; Global health; Health Diplomacy; International Technical Cooperation; Brazilian Foreign Policy. 


\section{Resumen}

Este artículo describe la evolución histórica de la cooperación técnica internacional de Brasil y su relación con la salud pública, marcando los momentos de inflexión conceptual y la perspectiva actual de Brasil sobre el tema. Analizar esta evolución histórica y conceptual y la participación de Brasil en la política sanitaria mundial es el propósito de este artículo, que tiene como método para el análisis documental, basado en revisión de la literatura y en la metodología cualitativa. El marco teórico se basa principalmente en autores de la política exterior brasileña, de la salud mundial y de la diplomacia de la salud, así como en los informes de las instituciones nacionales y multilaterales que participan de la cooperación técnica internacional en salud.

Palabras-clave: Salud Pública; Salud Global; Diplomacia de la Salud; Cooperación Técnica Internacional; Política Exterior Brasileña.

Declaração de conflito de interesses: não há.

Fontes de financiamentos: não há.

Considerações éticas: não há.

Histórico do artigo: Submetido: 27.fev.2016 | Aceito: 14.jun.2016 | Publicado: 30.set.2016.

Apresentação anterior

Licença CC BY-NC atribuição não comercial. Com essa licença é permitido acessar, baixar (download), copiar, imprimir, compartilhar, reutilizar e distribuir os artigos, desde que para uso não comercial e com a citação da fonte, conferindo os devidos créditos de autoria e menção à Reciis. Nesses casos, nenhuma permissão é necessária por parte dos autores ou dos editores. 


\section{Introdução}

A modalidade técnica da cooperação internacional adquiriu relevância para a política externa brasileira nas últimas décadas, especialmente na área da saúde pública, tema prioritário nas iniciativas brasileiras de cooperação técnica internacional.

Atrelada aos projetos de cooperação científica desenvolvidos pelas principais instituições brasileiras de ciência e tecnologia, mas dotada de teor iminentemente político, a cooperação técnica internacional brasileira operou considerável evolução histórico-conceitual ao longo da segunda metade do século XX ${ }^{\mathrm{i}}$ e, no início do século XXI, foi alçada, pelo Brasil, à condição político-estratégica.

Com efeito, o Brasil reformulou sua política de cooperação técnica internacional em saúde na atualidade, e o presente artigo analisa essa evolução histórico-conceitual e a inserção brasileira atual na política global da saúde. De país em desenvolvimento, tradicionalmente receptor de cooperação técnica, o Brasil adotou, nos últimos anos, postura proativa de engajamento e fornecimento de cooperação técnica internacional, prestigiando-se do teor geopolítico nessa nova postura.

\section{Relações Internacionais e direito à Cooperação Técnica Internacional}

A noção de cooperação internacional envolve muitas acepções e relaciona-se intrinsicamente com o próprio sentido de relações internacionais, enquanto processo de coordenação de políticas por meio do qual os atores ajustam seu comportamento às preferências reais ou esperadas dos outros atores ${ }^{1}$. O conceito de cooperação técnica, contudo, é bem mais recente, estando ligado ao processo europeu de reconstrução pós-Segunda Guerra Mundial.

A Resolução 200/1948, da Organização das Nações Unidas (ONU), instituiu formalmente a assistência técnica internacional e, por meio dela, lançou seu programa multilateral. Por assistência técnica entendiase a transferência, em caráter não comercial, de técnicas e conhecimentos, por meio da execução de projetos a serem desenvolvidos em conjunto entre atores de nível desigual de desenvolvimento - prestador e recipiendário ${ }^{\text {ii }}$ - envolvendo peritos, treinamento de pessoal, elaboração de material bibliográfico, aquisição de equipamentos, realização de estudos e pesquisas.

Os mecanismos criados ao fim da Grande Guerra ${ }^{\text {iii }}$ para pacificar e, principalmente, reconstruir a Europa Ocidental estabeleceram, em âmbito internacional, a cooperação técnica. Consistiam em empréstimos de elevados montantes de dinheiro, além da cessão de técnicos, serviços e materiais, transferidos de um Estado para outro, de modo unidirecional e com condicionalidades. Eram ofertados majoritariamente pelos Estados Unidos e pela União Soviética, como forma de ampliação de suas zonas de influência.

A cooperação técnica internacional (CTI) teve, pois, em sua origem, natureza assistencial e geopolítica, como modalidade de ajuda intergovernamental para a cooptação de aliados, no contexto bipolar da Guerra Fria.

"A inserção da CTI no sistema internacional ocorreu com as modificações introduzidas no imediato pós-guerra, entre 1945 e 1949. Falava-se então em "ajuda” para a reconstrução da Europa e para o desenvolvimento, porém as duas superpotências, Estados Unidos e União Soviética, tinham em vista, antes de tudo, a montagem de seus sistemas de aliança (Organização do Tratado do Atlântico Norte - OTANe Pacto de Varsóvia), bem como a preservação das zonas de influência com que haviam organizado o espaço

i A Constituição da República Federativa do Brasil ${ }^{11}$, estabeleceu a cooperação entre os povos como princípio brasileiro em suas relações exteriores $\left(\mathrm{CF}\right.$, art. $4^{\circ}$, IX).

ii A cooperação técnica internacional teve, pois, em sua origem, a noção de assistência, não propriamente de cooperação. A ideia de assistência contém, em seu bojo, as características de unilateralidade (condicionada) e de verticalidade, enquanto o conceito de cooperação traz intrínsecas as noções de bilateralidade (ou multilateralidade) e de horizontalidade, ou seja, comutatividade de direitos e deveres entre os cooperantes.

iii Erick Hobsbawm prefere falar em "Grande Guerra", pois, para ele, a Segunda Guerra Mundial foi corolário da Primeira, de modo que entende ser uma única guerra, com duas fases ${ }^{12}$. 
terrestre. A CTI nasceu, portanto, em contexto estratégico, não tendo como único escopo o que lhe era próprio, mas algo mais e distinto. Essa ambivalência entre fins próprios e a função derivada manter-se-á pelas décadas seguintes.”

Para Cervo $^{2}$, em sua acepção originára, a CTI envolveu os seguintes três elementos: a) transferência não-comercial de técnicas e conhecimentos; b) desnível quanto ao desenvolvimento alcançado por receptor e prestador; c) execução de projetos em conjunto, envolvendo peritos, treinamento de pessoal, material bibliográfico, equipamentos, estudos e pesquisas. A cooperação significava principalmente transferência de tecnologia no sentido Norte-Sul - dos países desenvolvidos para os em desenvolvimento -, de natureza vertical e unidirecional. Ao longo de décadas, pressupunha-se que os países do Norte detinham o “conhecimento", e que, por questão de justiça social, deveriam ofertá-lo aos em desenvolvimento.

Com o processo de descolonização na África e na Ásia e a ascensão do Movimento dos Não-Alinhados, o desenvolvimento tornou-se a principal agenda internacional dos países em desenvolvimento, que conseguiriam a criação da Conferência da ONU sobre Comércio e Desenvolvimento (UNCTAD), em 1964, e do Programa das Nações Unidas sobre o Desenvolvimento (PNUD), no ano seguinte, o qual gerenciaria a cooperação técnica internacional no âmbito das Nações Unidasv .

Em 1959, a Assembleia Geral da ONU aprovou a Resolução 1.383, que revia o conceito de assistência técnica e o substituía pela expressão cooperação técnica internacional, que, mais do que uma questão vocabular, representava um enfoque distinto, o qual engloba o direito ao desenvolvimento e o dever de cooperação por parte dos países industrializados. A noção de cooperação técnica traz em si mesma os sentidos de ética e de equidade e se baseia no interesse mútuo e na ajuda para fins de desenvolvimento ${ }^{\text {vi }}$.

Nesse contexto, surgiu a Abordagem das Necessidades Humanas Básicas (NHB) e a subsequente Cooperação Técnica entre Países em Desenvolvimento (CTPD, ou TCDC, em inglês), de cunho horizontal, cujo marco foi a Conferência das Nações Unidas sobre Cooperação Técnica entre Países em Desenvolvimento, em Buenos Aires, em 1978 (CTPD-Buenos Aires). Dessa conferência resultou o Plano de Ação de Buenos Aires, que a Assembleia Geral da ONU transformou na Resolução 33/134, de 19 de dezembro de 1978, e que representou, para o ex-diretor do PNUD, Denis Benn, o ponto alto da evolução da cooperação técnica entre os países em desenvolvimento.

"TCDC is a multidimensional process. It can be bilateral or multilateral in scope, and subregional, regional or interregional in character. It should be organized by and between Governments which can promote, for this purpose, the participation of public organizations and, within the framework of the policies laid down by Governments, that of private organizations and individuals. It may rely on innovative approaches, methods and techniques particularly adapted to local nedds and, at the same time, use existing modalities of technical co-operation to the extend that these are useful. While the main flows technical co-operation visualized would be between two or more developing countries, the support of developed countries and of regional and interregional institutions may be necessary."3,vii.

iv Acerca da noção de conhecimento em cooperação internacional, leia-se Torres, Rosa-Maria. ${ }^{13}$

v Desenvolvimento significava, à época, principalmente, crescimento econômico, e a cooperação técnica internacional era barganhada nas relações entre os Estados desenvolvidos e em desenvolvimento. O conceito de desenvolvimento iria modificar-se nas décadas seguintes, e abrangeria saúde, meio-ambiente, qualidade de vida, etc., assim como a cooperação técnica internacional, que ampliaria sua abrangência e adquiriria diversas modalidades.

vi "O sistema brasileiro de CTI, por trás do objetivo materialista, a movê-lo como se fosse sua alma, abrigou uma função humanista: preparar o homem para o domínio do conhecimento inerente ao controle do processo produtivo. 2

vii Tradução livre: A CTPD é um processo multidimensional. Ela pode ser bilateral ou multilateral no âmbito e sub-regional, regional ou inter-regional no caráter. Deve ser organizado para e entre os governos que podem promover, para o efeito, a participação de organizações públicas e, no âmbito das políticas estabelecidas pelos governos, a participação de organizações privadas e indivíduos. Pode confiar em abordagens inovadoras, métodos e técnicas particularmente adaptadas às necessidades locais e, ao mesmo tempo, usar as modalidades existentes de cooperação técnica, na medida em que estas são úteis . Enquanto os principais fluxos de cooperação técnica visualizado seriam entre dois ou mais países em desenvolvimento, o apoio dos países desenvolvidos e das instituições regionais e inter-regionais podem ser necessárias. 
Anecessidade denovos paradigmas contribui para a percepção de que a CTPDémeio idôneo à minimização das adversidades do processo de globalização. A Resolução 41/1992 do Conselho Econômico e Social da Organização das Nações Unidas (ECOSOC/ONU) convocou os países e o sistema de desenvolvimento da ONU a rever suas políticas e procedimentos, a fim de qualificar o debate da Cooperação Técnica entre os países em desenvolvimento e facilitar sua divulgação. A partir da Cúpula do Milênio, de 2000, e das Conferências que se seguiram, sem ressuscitar o obsoleto e desvalorizado terceiro-mundismo, seriam retomadas as premissas do dever internacional dos Estados de cooperarem e se ajudarem mutuamente na promoção do desenvolvimento.

A cooperação técnica internacional é então reconhecida como ferramenta essencial de política externa e de Direito Internacional, enquanto direito fundamental ao desenvolvimento e dever de solidariedade, cooperação e assistência global. Com efeito, o desenvolvimento é defendido por muitos Estados, na atualidade, como um direito universal, e a cooperação técnica internacional, um dever dos Estados, os quais devem permutar conhecimentos e técnicas, e convergir interesses em prol da melhoria nos níveis de vida de suas populações ${ }^{\text {viii }}$.

O Direito Internacional não contempla apenas a regulamentação do direito entre Estados, mas também o dos indivíduos e estabelece, em nossos dias, princípios de solidariedade que reforçam a aspiração por uma nova ordem mundial, regida por uma razão abrangente de humanidade, que pode encontrar expressão no conceito de globalização solidária, e que tem como corolário os Objetivos de Desenvolvimento do Milênio (ODS). A Declaração de Paris, concluindo o Segundo Fórum de Alto Nível sobre a Efetividade da Ajuda, em 2005, e sua posterior ratificação na Declaração de Acra (2008) revelam esse processo ${ }^{\text {ix }}$. Apropriação, alinhamento, harmonização, gestão centrada em resultados e responsabilização mútua foram as estratégias escolhidas para a cooperação internacional.

Desde então, a cooperação técnica internacional trabalha sobre três vertentes principais, quais sejam: a cooperação tradicional recebida de países desenvolvidos, a recebida de organismos internacionais e a cooperação horizontal, também chamada Sul-Sul. Acordos são firmados envolvendo projetos técnicos. A função do projeto de cooperação técnica internacional é capacitar e instrumentalizar órgãos públicos para que estes possam implementar, por seus próprios meios, de forma eficiente e sustentável, políticas públicas ${ }^{x}$.

Para Valler Filho 4 , o conceito de CTI representa um consenso tênue entre as posições paternalistas dos países desenvolvidos e as reivindicações daqueles em desenvolvimento no que diz respeito a relações internacionais equânimes, não se traduzindo em conceito unânime ou pacífico. Subjacente a ele, trata-se, de fato, da existência do direito ao pleno desenvolvimento econômico e social, direito que seria inalienável e independeria da vontade unilateral dos países prestadores de cooperação.

viii Não por outra razão, o Brasil inseriu o dever de cooperar com outras nações como princípio fundamental de suas relações internacionais.

ix The Paris Declaration (2005) is a practical, action-oriented roadmap to improve the quality of aid and its impact on development. It gives a series of specific implementation measures and establishes a monitoring system to assess progress and ensure that donors and recipients hold each other accountable for their commitments. Designed to strengthen and deepen implementation of the Paris Declaration, the Accra Agenda for Action (AAA, 2008) takes stock of progress and sets the agenda for accelerated advancement towards the Paris targets". ${ }^{14}$

x Policy transfer ou transeferência de políticas públicas. 


\section{Diplomacia da saúde e cooperação}

A saúde é hoje compreendida como resultado de uma série de fatores determinantes, relacionados com as condições de vida e de bem-estar, como a pobreza e o grau de desenvolvimento da sociedade, os denominados determinantes sociais da saúde, que ampliam a noção de saúde, de seus aspectos meramente relacionados à pessoa, para condicioná-la também às sociedades e às relações entre estas ${ }^{\mathrm{xi}}$.

Além disso, a capacidade dos Estados nacionais de lidarem com as questões relativas à saúde é cada vez mais limitada, reconhecendo-se a emergência dos conceitos de saúde global e diplomacia da saúde ${ }^{\mathrm{xii}}$, cuja governança transborda os mecanismos políticos tradicionais de controle estatal. Eles se relacionam com a noção de determinantes sociais e com a percepção de que, na atualidade, os problemas de saúde muitas vezes afetam todas as sociedades e, por isso, devem ser globalmente geridos.

Para Alcazar ${ }^{5}$, o processo de socialização das relações internacionais em saúde representou uma verdadeira mudança de paradigma, ao que denominou "Revolução Copernicana", pois, a partir de então, os temas tradicionais das relações internacionais, como segurança, comércio e investimentos, ficariam subordinados a questões de natureza social, como saúde, meio ambiente e direitos humanos. Atribuir-se-ia, desde então, às relações exteriores e ao direito internacional, uma função social, e saúde e bem-estar ou qualidade de vida tornam-se sinônimos. O desenvolvimento econômico cedeu espaço para o desenvolvimento social.

A saúde global passa, nesse contexto, a ser compreendida como uma das áreas da nova abordagem diplomática, em um estágio contemporâneo de globalização, onde a saúde é fruto do desenvolvimento econômico, político e social. Não há desenvolvimento sem saúde nem saúde sem desenvolvimento. Disseminação de doenças emergentes, ajuda humanitária, transição epidemiológica, compromissos internacionais, como as metas de desenvolvimento do milênio e o debate entre saúde pública e questões comerciais, são assuntos relacionados a essa conjunturaxiii.

A cooperação técnica internacional apresenta-se hoje, nesse contexto, como valioso instrumento de promoção da saúde e do desenvolvimento, além de agenda de política externa em saúde, cumprindo papel preponderante na melhoria dos sistemas de saúde dos países que a utilizam com regularidade. Ela acompanhou, historicamente, a evolução do instituto da CTI.

Críticas contribuíram para essa evolução do conceito e do próprio instituto da cooperação técnica internacional em saúde. Alleyne ${ }^{6}$ destaca a noção tradicional de doador versus recebedor de cooperação, por um lado; e os altos custos dos projetos, que exigiam longos períodos e altos recursos, por outro, como os principais problemas do modelo tradicional.

A emergência da horizontalidade, no âmbito da saúde, ampliou o espectro de questões tratadas e pode focar nos problemas específicos dos Estados cooperantes, inclusive com a possibilidade de aprendizado conjunto, baseado em problemas comuns, por exemplo entre países tropicais, que têm enfermidades comuns relacionadas ao clima.

Apesar dessa evolução, em ensaio crítico, Sridhar7 discute a importância, ainda hoje, da assistência para a saúde global e demonstra o alto teor político que envolve a diplomacia da saúde. Revela que, a despeito da pequena parcela da assistência no orçamento global para a saúde, de apenas $0,3 \%$, muitos países são

\footnotetext{
xi Para uma melhor compreensão da saúde na atualidade, vide Buss e Pellegrini Filho ${ }^{15}$

xii Os conceitos de saúde global e diplomacia da saúde são recentes e ainda relativamente pouco definidos. Incluem os problemas de saúde cuja preocupação ultrapassa as fronteiras estatais, mas consideram as próprias relações globais que influem nas condições de vida das pessoas, condicionando o comportamento dos Estados e suas politicas externas. Sobre os conceitos, ler Kickbusch e Berger ${ }^{16}$

xiii O discurso do então chanceler Celso Amorim, na $60^{\mathrm{a}}$ Assembleia Geral da OMS, a convite do então ministro de Estado da Saúde, José Gomes Temporão, defendendo o licenciamento compulsório do antirretroviral efavirenz, é representativo dessa realidade.
} 
dependentes exclusivamente dessa contribuiçãa ${ }^{\text {xiv }}$. Critica o fraco envolvimento dos governos com a saúde, majoritariamente relacionada à industria da saúde, e o foco das políticas externas em saúde apenas em vigilância e controle de doenças infecciosas.

\section{A política externa brasileira de cooperação técnica internacional em saúde}

Data dos anos 1970 a estreita vinculação da cooperação técnica internacional com as políticas públicas de desenvolvimento no Brasil. Os programas e projetos contemplados com recursos externos passariam a ser determinados pelas diretrizes definidas nos Planos Nacionais de Desenvolvimento (PNDs) e priorizariam projetos estruturais e o desenvolvimento de capacidades autônomas.

O programa de cooperação prestada seria de fato iniciado em 1971, mediante a assinatura do Acordo sobre a Realização de um Programa de Cooperação Técnica com o Paraguai (Assunção, 05/05/1971), do Acordo Relativo à Execução de Projetos de Cooperação Técnica com a Colômbia (Brasília, 08/06/1971), do Acordo Relativo à Criação de uma Comissão Mista de Cooperação Técnica, Econômica e Comercial com Trinidad e Tobago (Port of Spain, 09/11/1971) e do Aide Mémoire sobre Cooperação Técnica com a Guiana (Georgetown, 11/11/1971), e moldava-se através de negociações simultâneas nas frentes internas e externas.

Externamente, seriam negociados acordos com vários países latino-americanos e africanos. Procurou-se também enfatizar, nos foros multilaterais, a importância da cooperação horizontal e obter o apoio do PNUD para ações de CTPD. Internamente, várias instituições - nos âmbitos federal e estadual - seriam convocadas a colaborar na prestação de cooperação técnica a terceiro países, dentre elas a Empresa Brasileira de Pesquisa Agropecuária (EMBRAPA), a Fundação Oswaldo Cruz (FIOCRUZ), o Serviço Nacional de Aprendizagem Industrial (SENAI), o Serviço Brasileiro de Apoio às Micro e Pequenas Empresas (SEBRAE), o Ministério da Saúde e o Ministério da Educação.

Enquanto a cooperação técnica recebida era vista como propulsora do desenvolvimento e de mudanças estruturais no Brasil, a cooperação prestada pelo País passaria a representar um instrumento de política externa, com objetivos específicos, contribuindo para o estreitamento dos vínculos políticos, culturais e comerciais do País na dimensão Sul-Sul.

"O objetivo principal desse mecanismo, na época, seria o de afirmar o Brasil como potência emergente, mediante a demonstração de sua capacidade tecnológica. A cooperação técnica veio a ser ainda oportuna na abertura de vias de entendimento com países em desenvolvimento, em especial os da América Latina e da África, e na promoção de exportações. Esperava-se, também, com essa política, conseguir o aprofundamento das relações com outros países em desenvolvimento, a fim de facilitar a articulação conjunta dos países do Terceiro Mundo nos foros internacionais." 4

Oportuno diferenciar a cooperação oficial e a cooperação interinstitucional no Brasil. A primeira é regulada por acordos internacionais e ocorre entre o Governo brasileiro e os governos de outros países (cooperação bilateral, tanto recebida quanto prestada), ou entre o Governo do Brasil e Organismos Internacionais (cooperação multilateral). Entre as modalidades de cooperação tratadas pelo Governo brasileiro distinguem-se a técnica, a científico-tecnológica e a financeira. A cooperação interinstitucional ocorre entre instituições públicas e/ou privadas de países diferentes, através de convênios entre as partes envolvidas.

A cooperação técnica possibilita o repasse de técnicas estabelecidas e usualmente praticadas e configura-se em mecanismo de transferência de know-how, informações ou conhecimentos técnicos, além do treinamento de pessoal em áreas diversas. Normalmente, ela se relaciona com políticas domésticas de desenvolvimento e com a política externa, coaduna-se e complementa as outras modalidades de cooperação.

xiv Diversamente da representatividade da assistência no orçamento global da saúde, ela responde por parcela considerável do orçamento de alguns países subdesenvolvidos, principalmente na África. 
No caso da saúde, a cooperação internacional do Brasil envolve parcerias tanto no sentido NorteSul quanto no Sul-Sul, sendo prestada em maior escala a cooperação técnica e em menor a científica e tecnológica, sendo que o Ministério da Saúde (MS) costuma receber mais do que prestar em termos de cooperação. As ações internacionais do MS são coordenadas pela Assessoria de Assuntos Internacionais, que tem como objetivo "conciliar de maneira harmônica as políticas nacionais de saúde e a política externa nacional, e assim evitar a dispersão de esforços técnicos”.

A Organização Pan-Americana da Saúde (Opas) e a Agência Brasileira de Cooperação (ABC) são os principais foros dessas iniciativas, sendo a primeira ligada à Organização Mundial da Saúde e a segunda ao Ministério das Relações Exteriores do Brasil. A Opas tem como estratégias de cooperação técnica a mobilização de recursos, a disseminação de informação, a formação de pessoal, a formação de planos, normas e políticas, o fomento à investigação e o assessoramento técnico direto. Já a ABC é a agência ministerial de relações exteriores voltada para a cooperação técnica entre instituições brasileiras e estrangeiras, e tem como atribuição "negociar, coordenar, implementar e acompanhar os programas e projetos brasileiros de cooperação técnica, executados com base nos acordos firmados pelo Brasil com outros países e organismos internacionais"'.

No ano de 2005, a Opas/OMS e o Brasil firmaram o Termo de Cooperação no 41 (TC 41) - Programa de Saúde Internacional (PSI) -, com o objetivo de desenvolver um programa de cooperação internacional em saúde voltado para o intercâmbio de experiências, conhecimentos e tecnologias disponíveis em instituições do campo da saúde pública no Brasil e nos países integrantes da Opas/OMS, com prioridade para a América do Sul e os Países Africanos de Língua Oficial Portuguesa (Palop), no marco da Cooperação Sul-Sul. O TC 41 surge no contexto das mudanças políticas e institucionais imbuídas de interesses voltados para ampliação do protagonismo brasileiro no campo internacional, inclusive na área da saúde, representando uma forma de potencializar o intercâmbio de conhecimentos e tecnologias úteis no enfrentamento dos problemas de saúde.

Ato contínuo, o Brasil formulou estratégia de cooperação técnica em saúde, a cooperação Sul-Sul estruturante em saúde, a qual considera os problemas sociais comuns e a identidade histórica dos países em desenvolvimento. Ela oferece o quadro teórico geral para a cooperação técnica em saúde das instituições brasileiras e é defendida nos fóruns multilaterais da saúde, notadamente na OMS. Vale-se da Cooperação Técnica entre os Países em Desenvolvimento (CTPD), seguindo as diretrizes gerais do Plano de Ação de Buenos Aires e os valores e princípios da Declaração de Paris (2005) e da Agenda de Ação de Acra (2008).

Prioriza ações de cooperação técnica no âmbito das redes internacionais de saúde, de que são exemplos a Rede de Institutos Nacionais de Saúde (RINS), a Rede de Escolas Nacionais de Saúde Pública (RESP), a Rede Internacional de Formação de Técnicos em Saúde (RETS), pois nelas é possível a troca de experiências e o aprendizado conjunto acerca de problemas de saúde locais, regionais e globais, de forma democrático-cooperativa.

"O Brasil ainda não fazia cooperação porque não tinha dinheiro para fazer. Então, uma vez que houve essa disponibilidade de recursos, começamos a pensar a possibilidade de negociar um projeto, que desde o princípio deveria essencialmente tratar de reforçar a estrutura do serviço de saúde ("ser estruturante"), mais do que tratar de doenças do tipo do projeto norte e sul, que é AIDS, tuberculose, Malária, etc. Essas doenças todas viriam no bojo de melhoria do sistema de saúde. Sistema de saúde que não é só doença, que inclui desde os determinantes sociais da saúde, uma quantidade de elementos que independem da doença e que deveriam ser tratados até prioritariamente, se quiséssemos que os projetos tivessem alguma sustentabilidade. É em função disso que surge a ideia de sustentabilidade."xv

A cooperação estruturante em saúde pressupõe uma integração entre países com problemas comuns de saúde, valoriza os conhecimentos e as práticas locais e baseia-se na construção de capacidades para

XV Ferreira, apud ${ }^{9}$ 
o desenvolvimento. Tem como pilares a formação de recursos humanos, o fortalecimento organizacional e o desenvolvimento institucional. É estruturante porque centrada no fortalecimento institucional dos sistemas de saúde, e é Sul-Sul porque baseada na cooperação horizontal, com prioridade para os países em desenvolvimento, especialmente os sul-americanos e os PALOPS.

Almeida, Campos, Buss, Ferreira e Fonseca1o listam como aspectos estratégicos da posição brasileira sobre cooperação estruturante em saúde: "priorização da cooperação horizontal"; "foco no desenvolvimento de capacidades em saúde"; "iniciativas coordenadas no contexto regional"; "envolvimento dos ministros da saúde na construção de consensos estratégicos e políticos"; e "estímulo à parceria nacional entre Ministério da Saúde e Ministério das Relações Exteriores”.

O entorno subcontinental americano é zona prioritária da política externa brasileira contemporânea, e teve como ponto de partida a aproximação entre o Brasil e a Argentina no período de redemocratização de ambos, a partir da década de 1980, com a instituição do Mercado Comum do Sul (Mercosul), em 1994, e da União dos Países Sul-Americanos (Unasul), já nos anos 2000, trilhando-se o caminho para alcançarem o "destino comum” "xi que lhes é cabido. A cooperação em saúde também segue essa estratégia, cabendo à Fundação Oswaldo Cruz (Fiocruz) organizar ou participar de cooperação técnica com todos os países da região, em temas definidos como prioritários e expostos pelo Plano Quinquenal Unasul - Saúde (2011-2015): vigilância epidemiológica sul-americana; sistemas universais de saúde; acesso universal a medicamentos; gestão e desenvolvimento de recursos humanos; e programa de bolsas de estudo em saúde. Considerem-se dois eventos estruturantes no processo de consolidação da UNASUL, em 2008, a criação do seu Conselho Sul-Americano de Saúde, composto por 12 ministros de Estado da saúde, e, em 2010, a criação do Instituto Sul-Americano de Governo em Saúde (ISAGS).

O documento "Iniciativas para o setor saúde no Cone Sul: cooperação em formação de recursos humanos, pesquisa, desenvolvimento tecnológico e produção de insumos em saúde”, de 1998, ressalta a complementaridade como conceito-chave para a cooperação em saúde na América Latina e lista como alguns dos obstáculos ao aperfeiçoamento dessa cooperação a fragilidade dos mecanismos de coordenação das redes, a presença ainda incipiente do tema saúde no Mercosul, a descontinuidade das iniciativas, o pouco contato com instituições financiadoras e a descontinuidade dos financiamentos. Destaca o papel da Oficina Pan-Americana em Saúde (Opas) como entidade condutora dessa complementaridade e como interlocutora decisiva para a obtenção de financiamentos junto a Estados membros, ao BID, BIRD, ao Sistema Econômico Latino Americano e Caribenho (Sela) etc.

Outra prioridade da política externa brasileira em saúde são os Palops, pertencentes à Comunidade dos Países de Língua Portuguesa (CPLP). Integram a CPLP os ministros de Estado da Saúde de Angola, Brasil, Cabo Verde, Guiné-Bissau, Moçambique, Portugal, São Tomé e Príncipe e Timor Leste, em conjunto com os respectivos pontos focais locais. Por demanda do MS brasileiro, a Fiocruz assumiu diversos projetos institucionais na África.

Em Moçambique, na capital Maputo, em 2007, a Fiocruz inaugurou um escritório regional que vem contribuindo, através de farmanguinhos/Fiocruz, na consolidação de uma fábrica de medicamentos, vinculada ao Ministério da Saúde daquele país. Também em Maputo, a Fiocruz colaborou na criação de uma Escola Politécnica e desenvolve um programa de mestrado e de doutorado em ciências de saúde. Em Angola, há programa de mestrado em saúde pública e negocia-se a criação de uma Escola Nacional de Saúde Pública. Na Guiné Bissau os projetos são para a criação de uma Escola Técnica em Saúde, e negociase um Instituto Nacional. Por fim, em Cabo Verde, há parceria para uma Escola Técnica em Saúde e para a aplicação de curso de doutorado em saúde pública.

xvi Expressão cunhada pelo embaixador José Botafogo para referir-se à integração latino-americana. Para o também embaixador Antonio Simões essa integração somente será possível por meio da "diplomacia da jurisdicidade", que consiste na criação de valores comuns à região. 
No ano de 2015, terminou o prazo do TC41 entre a OPAS e o MS, e aquela organização publicou um trabalho de avaliação dos resultados do acordo, intitulado "Avaliação do Programa de Cooperação Internacional em Saúde: Intercâmbio de experiências, conhecimentos e tecnologias entre instituições do campo da saúde pública no Brasil e nos países integrantes da OPAS/OMS”. No geral, houve a percepção de que o TC41 foi positivo, mas muitas críticas foram feitas à gestão da cooperação técnica brasileira em saúde.

Para o cordenador adjunto do Centro de Relações Internacional em Saúde da Fiocruz (CRIS/Fiocruz), Dr. José Roberto Ferreira, em entrevista concedida para aquele Relatório, o Brasil não fez cooperação estruturante, apesar de ter contribuído com alguns sistemas de saúde, principalmente o de Moçambique. Para ele, ainda, a proposta de trabalho em redes não funcionou, tendo sido os projetos trabalhados sempre bilateralmente.

\section{Conclusão}

A cooperação internacional ganhou relevância e amplitude nas últimas décadas, e a cooperação técnica internacional tornou-se, como visto, objeto da politica externa dos Estados. O Brasil utilizou-se largamente dessa modalidade de cooperação internacional nos últimos anos, especialmente na área da saúde, para a qual formulou-se, como visto, doutrina e estratégia própria.

A análise retrospectiva da cooperação internacional e da cooperação técnica internacional em saúde permite avaliar positivamente a política externa brasileira de cooperação em saúde, considerando-se o direito internacional contemporâneo e a saúde global.

Todavia, como visto, o Relatório de avaliação final do TC41 entre a OPAS e o Ministério da Saúde revelou problemas sensíveis nos projetos brasileiros de cooperação técnica internacional em saúde, que colocam em dúvida, até mesmo, a viabilidade do modelo estruturante de cooperação.

Caberá, pois, a reavaliação da cooperação técnica internacional em saúde para os próximos anos, a qual estará condicionada a questões diversas envolvendo a governança global, o direito e as relações internacionais, considerando-se a interdisciplinariedade e os interesses múltiplos relacionados à agenda global da saúde.

\section{Referências}

1. Keohane R. After Hegemony: Cooperation and Discord in the World Political Economy. New Jersey: Princeton University Press; 1984.

2. Cervo AL. Socializando o desenvolvimento: uma história da cooperação técnica internacional do Brasil. Rev. Bras. Polít. Int. 37(1):37-63, 1994.

3. UNDP. The Buenos Aires Plan of Action. New York: ONU; 1978. [citado 13 out. 2015.] Disponível em: http://unfccc.int/resource/docs/cop4/16a01.pdf.

4. Valler Filho W. O Brasil e a Crise Haitiana: a cooperacão técnica como instrument de solidariedade e de ação diplomática. Brasília: Funag; 2007.

5. Alcazar S. The Copernican Shift in Global health. The graduate institute, Geneva: Global Health Programme, working paper n. 3, 2008.

6. Alleyne, AOG. Hacia uma taxonomia de la cooperación técnica em salud. Bol of Sanit Panam, 112(1):1-11, 1992.

7. Sridhar D. Seven challenges in international development assistance for health and ways forward. Journal of law, medicine \& ethics, 38(3):459-469, 2010.

8. Agência Brasileira de Cooperação. Cooperação técnica brasileira em saúde. Via ABC. Boletim eletrônico da Agência Brasileira de Cooperação (ABC/MRE), mar. 2007. [citado 5 jul. 2014] Disponível em: http:// www..abc.gov.br/documentos/viaABC-baixa.pdf.

9. OPAS. Avaliação do Programa de Cooperação Internacional em Saúde: Intercâmbio de experiências, conhecimentos e tecnologias entre instituições do campo da saúde pública no Brasil e nos países integrantes da OPAS/OMS. Brasília, 2015. 
10. Almeida C, Campos RP, Buss P, Ferreira JR, Fonseca, IE. A concepção brasileira de "cooperação Sul-Sul estruturante em saúde". R. Eletr. de Com. Inf. Inov. Saúde, 4(1):25-35, 2010.

11. Brasil. Presidência da República. Constituição da República Federativa do Brasil. 1988. [Citado 7 jun. 2016] Disponível em: http://www. planalto.gov.br/ccivil 03/constituicao/constituicaocompilado.htm.

12. Hobsbawm EJ. A era dos extremos: o breve século XX. Rio de Janeiro: Companhia das Letras; 1996.

13. Torres RM. Cooperação internacional baseada em conhecimento: nós a queremos? E precisamos dela? Buenos Aires: Instittuto Fronesis; 2001.

14. OECD. Paris Declaration on Aid Effectiveness: Ownership, Harmonisation, Alignment, Results and Mutual Accountability. High Level Forum on Aid Effectiveness. Paris. 2005. [Citado 2 set. 2015] Disponível em: http://www.oecd.org/dac/effectiveness/parisdeclarationandaccraagendaforaction.htm.

15. Buss PM, Pelegrini Filho A. A saúde e seus determinantes sociais. PHYSIS: Rev. Saúde Coletiva, Rio de Janeiro, 17(1):77-93, 2007. [Citado 25 abr. 2016] Disponível em: http://www.scielo.br/pdf/physis/ v17n1/v17n1a06.pdf.

16. Kickbusch I, Berger C. Global Health Diplomacy. R. Eletr. de Com. Inf. Inov. Saúde., Rio de Janeiro, $4(1): 18-22,2010$. 